\title{
Prehospital Tourniquets in Civilians: A Systematic Review
}

\author{
Kenneth A. Eilertsen, MS; ${ }^{1}$ Morten Winberg, MS; ${ }^{1}$ Elisabeth Jeppesen, MPH, PhD; $;{ }^{2,3}$ Gyri Hval, BSc; ${ }^{4}$ \\ Torben Wisborg, $\mathrm{MD}, \mathrm{PhD}^{5,6,7}$
}

Note: Eilertsen and Winberg are co-first authors.

1. University of Oslo, Oslo, Norway

2. Faculty of Health Sciences, University of Stavanger, Stavanger, Norway

3. Department of Research, The Norwegian Air Ambulance Foundation, Oslo, Norway

4. Norwegian Institute of Public Health, Oslo, Norway

5. University of Tromsø, The Arctic University of Norway, Hammerfest, Norway

6. Dept. of Anaesthesia and Intensive Care, Hammerfest Hospital, Finnmark Health Trust, Hammerfest, Norway

7. Norwegian National Advisory Unit on Trauma, Division of Emergencies and Critical Care, Oslo University Hospital, Oslo, Norway

Correspondence:

Torben Wisborg, MD, PhD

Professor, University of Tromsø

The Arctic University of Norway

Hammerfest, Norway

E-mail: torben.wisborg@traumatologi.no

Conflicts of interest/funding: The authors declare no conflicting interests. There was no external funding, departmental funding only.

Keywords: first responder; hemorrhage; penetrating wounds; tourniquet

\section{Abbreviations:}

EMS: Emergency Medical Services

GRADE: Grading of Recommendations

Assessment Development and Evaluation

ICTRP: International Clinical Trials Registry Platform

WHO: World Health Organization

Received: June 26, 2020

Accepted: July 30, 2020

\section{Abstract}

Objectives: Terrorist attacks and civilian mass-casualty events are frequent, and some countries have implemented tourniquet use for uncontrollable extremity bleeding in civilian settings. The aim of this study was to summarize current knowledge on the use of prehospital tourniquets to assess whether their use increases the survival rate in civilian patients with life-threatening hemorrhages from the extremities.

Design: Systematic literature review in Medline (Ovid), Embase (Ovid), Cochrane Library, and Epistemonikos was performed using the Preferred Reporting Items for Systematic Reviews and Meta-Analyses (PRISMA) Guidelines. The search was performed in January 2019.

Setting: All types of studies that examined use of tourniquets in a prehospital setting published after January 1, 2000 were included.

Primary/Secondary Outcomes: The primary outcome was mortality with and without tourniquet, while adverse effects of tourniquet use were secondary outcomes.

Results: Among 3,460 screened records, 55 studies were identified as relevant. The studies were highly heterogeneous with low quality of evidence. Most studies reported increased survival in the tourniquet group, but few had relevant comparators, and the survival benefit was difficult to estimate. Most studies reported a reduced need for blood transfusion, with few and mainly transient adverse effects from tourniquet use.

Conclusion: Despite relatively low evidence, the studies consistently suggested that the use of commercial tourniquets in a civilian setting to control life-threatening extremity hemorrhage seemed to be associated with improved survival, reduced need for blood transfusion, and few and transient adverse effects.

Eilertsen KA, Winberg M, Jeppesen E, Hval G, Wisborg T. Prehospital tourniquets in civilians: a systematic review. Prehosp Disaster Med. 2021;36(1):86-94.

\section{Introduction}

Trauma in the civilian setting may differ from trauma in the military, but the last decades' terrorist attacks and mass-casualty events world-wide have made penetrating injuries more similar in the two settings than before. Therefore, knowledge from both settings can be valuable when informing national guidelines. This new panorama of injuries, often with multiple casualties occurring at the same time, has forced a re-evaluation of treatment and first responder recommendations. In the US, early hemorrhage control has become a central focus for improving survival in life-threatening extremity bleeding following the Hartford Consensus. ${ }^{1-4}$ They recommend that civilian bystanders, law enforcement officers, and Emergency Medical Services (EMS) personnel be equipped with and use tourniquets.

In the last few years, Europe has had numerous terrorist attacks and mass-casualty events, including Oslo/Utøya 2011, Paris 2015, Nice 2016, and Berlin 2016. After the July 22, 2011 attacks in Norway, ${ }^{5}$ the Norwegian Directorate of Health (Oslo, Norway) published a report in which one of the recommendations was to establish updated national guidelines for the

\section{doi:10.1017/S1049023X20001284}

(C) The Author(s), 2020. Published by Cambridge University Press on behalf of the World Association for Disaster and Emergency Medicine. This is an Open Access article, distributed under the terms of the Creative Commons Attribution licence (http://creativecommons.org/licenses/by/4.0/), which permits unrestricted re-use, distribution, and reproduction in any medium, provided the original work is properly cited. 
use of tourniquets by police officers. Few countries have coherent national guidelines for the use of tourniquets. Some systematic reviews already exist on the subject, but few had sufficiently broad search strategy, were published in English, and included both military and civilian studies. A new systematic review was therefore considered necessary.

This systematic review aims to summarize current knowledge of the use of prehospital tourniquets to be used as a theoretical framework for developing guidelines for prehospital treatment in civilian settings. The primary outcome was to assess whether the use of prehospital tourniquets increases the survival rate in civilian patients with life-threatening hemorrhage from the extremities. Secondary outcomes were number of transfusions, complications, and other adverse events, if available.

\section{Methods}

To conduct this systematic review, the Preferred Reporting Items for Systematic Reviews and Meta-Analysis (PRISMA) Guidelines ${ }^{6}$ were utilized (checklist is included in Appendix I; available online only). The protocol was published on PROSPERO (ID-number: CRD42019123172).

\section{Differences between Protocol and Review}

As described in the Introduction, penetrating injuries in civilian settings are more similar to such injuries in military settings now than they were before. Studies in military settings were therefore included. It was suspected that there would be few controlled studies on this intervention, and all types of study designs were identified. However, only studies with more than 20 cases were included in the primary outcome (mortality). All studies were included when assessing the secondary outcomes (blood transfusions, complications of the extremity, or other adverse events) to identify rare complications. These decisions were made before the search was done and before the inclusion process.

\section{Inclusion Criteria}

To identify all relevant studies on the topic, the following inclusion criteria were used: (1) Population: Adult patients aged $\geq 16$ with lifethreatening hemorrhages from the extremities; (2) Intervention: Treatment with tourniquet by professionals or laymen; (3) Comparison: Hemorrhage control with other measures; (4) Outcomes: Mortality, number of blood transfusions, complications of the extremity, and other adverse events - studies had to report on patient outcomes; (5) Study Design: All studies with more than 20 informants for primary outcome and all studies for secondary outcomes; (6) Language: All languages that could be translated by automatic translation engines were included, however, Cyrillic and Chinese papers were excluded; and (7) Publication Year: Studies published from 2000 onwards.

\section{Literature Search}

The following electronic databases were searched for eligible studies on January 10, 2019: Medline (Ovid; US National Library of Medicine, National Institutes of Health; Bethesda, Maryland USA), Embase (Ovid; Elsevier; Amsterdam, Netherlands), Cochrane Library (The Cochrane Collaboration; London, United Kingdom), and Epistemonikos (Epistemonikos Foundation; Santiago, Chile). The search was limited to studies published from 2000 onwards. PROSPERO, clinicaltrials.gov, and World Health Organization International Clinical Trials Registry Platform (WHO ICTRP; Geneva, Switzerland) were searched for planned and on-going studies. The search was peerreviewed and is documented in Appendix II (available online only).

In addition to the electronic search, the reference lists of included studies and systematic reviews were searched.

\section{Study Selection and Data Extraction}

The records identified from different sources were collated into a systematic review screening tool (RAYYAN; Qatar Computing Research Institute; Doha, Qatar) ${ }^{7}$ in which duplicates were removed. References obtained from database and literature searches were independently examined at the title/abstract level by two authors, with discrepancies resolved by consensus, and then retrieved as complete articles if determined to be potentially pertinent. The studies were included if they met the inclusion criteria. The search results were exported to EndNote (Clarivate; Philadelphia, Pennsylvania USA). ${ }^{8}$

Some of the studies reported data from the same population/ database. In that case, only data extracted from the latest published study with the largest sample size that reported relevant outcomes were used.

\section{Quality Appraisal}

The Critical Appraisal Skills Programme (CASP; Oxford, United Kingdom) checklist for critical appraisal of observational studies was employed. ${ }^{9}$ The critical appraisal was done by KAE and MW, and discrepancies resolved through discussion. No randomized controlled studies were identified; therefore, all relevant published material was systematically reviewed - independent of study design. Case reports were only included to assess secondary outcomes. The reliability of the evidence was assessed using the Grading of Recommendations Assessment, Development, and Evaluation (GRADE) approach. ${ }^{10}$ The certainty of the evidence was rated as low or very low due to the observational designs, high risk of bias, and uncertain "dose-responds."

\section{Definitions}

A civilian setting is a study that describes civilian patients treated by non-military personnel, such as EMS personnel, doctors, laymen, fire constables, and police enforcement in a civilian environment. A military setting is a study that describes patients (military personnel and civilians) treated by military personnel (medics, soldiers, and military hospitals) in a warfare environment. A tourniquet is a constricting or compression device used to control arterial and venous blood flow to a portion of an extremity for a period of time. An improvised tourniquet is a tourniquet made from materials originally not intended to be used as a tourniquet, such as belts and clothes. A commercial tourniquet is a commercially available product made solely to be used as a tourniquet.

\section{Patient and Public Involvement}

No patients were involved in the design of the study. The study was not commissioned, and there was no public involvement.

\section{Results}

Included Studies

After duplicate removal, 3,116 studies were identified. Title and abstracts were screened for eligibility, and the remaining 185 studies were screened for eligibility through full-text review. Finally, 112 studies were excluded. A total of 344 on-going studies were identified at clinicaltrials.gov, WHO ICTRP, and PROSPERO. This resulted in 73 eligible studies. Another four studies were included after reviewing the reference lists of the systematic reviews and literature reviews. Two of the studies were not found in the original search, one because it was published before $2000^{11}$ 


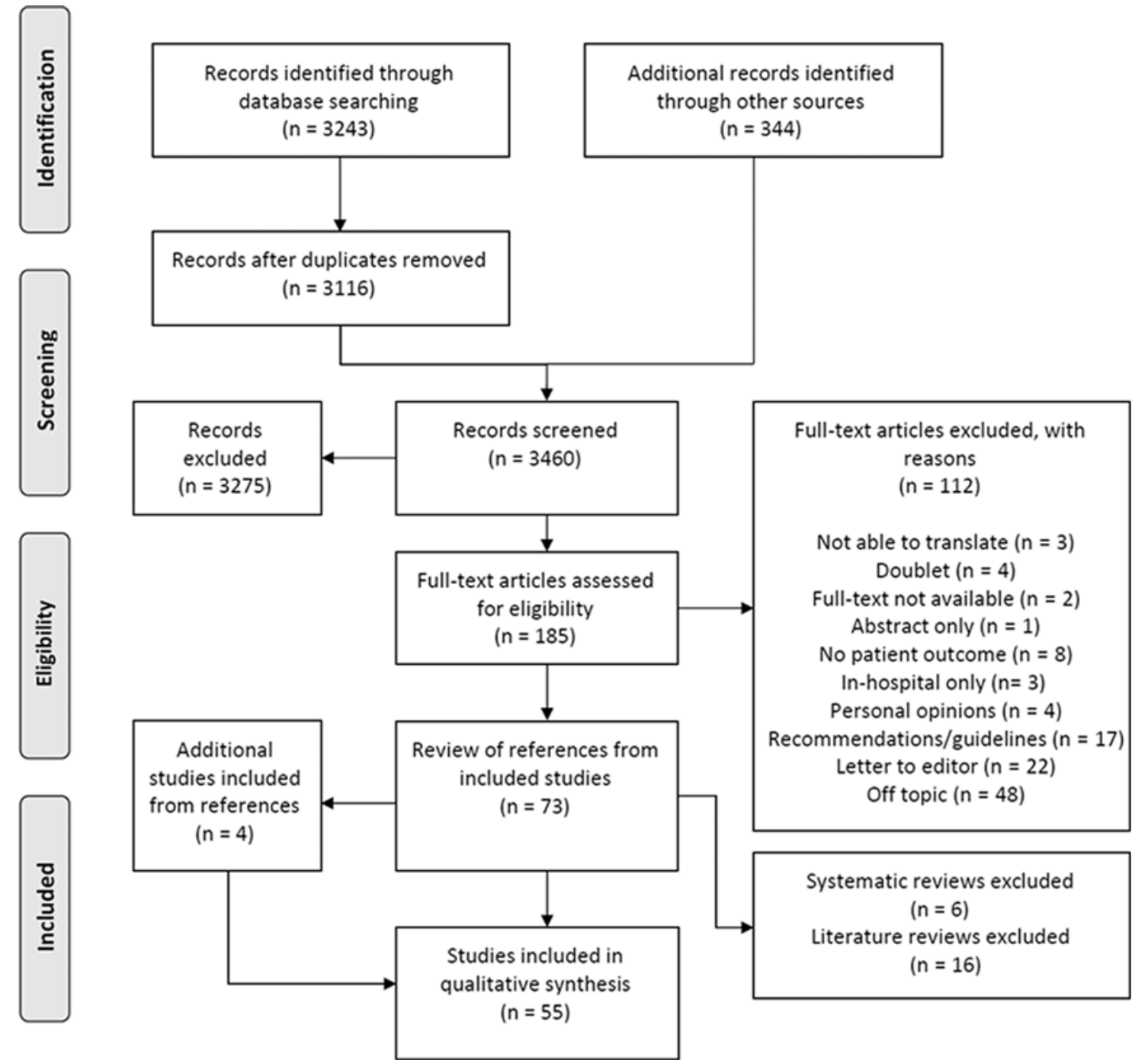

Eilertsen () 2021 Prehospital and Disaster Medicine

Figure 1. PRISMA Flow Diagram of the Selection of Included Studies.

and the other because tourniquet was not mentioned in the title or abstract. ${ }^{12}$ Two more studies were originally excluded from the title and abstract review, but were included after reading the full-text from references: one case report ${ }^{13}$ and one literature review. ${ }^{14}$ After excluding all non-primary literature such as literature reviews ${ }^{14-29}$ and systematic reviews, ${ }^{30-35}$ a total of 55 studies were included in this systematic review. The process from search result to inclusion is illustrated in Figure 1.

\section{Quality of Evidence}

All included studies were published from January 1, 2000 through January 10, 2019 and consisted of 15 civilian retrospective observational studies, ${ }^{36-50}$ two civilian case series, ${ }^{51,52} 12$ civilian case reports, ${ }^{13,53-63}$ six prospective observational military studies, ${ }^{64-69}$ 16 military retrospective observational studies, ${ }^{11,12,70-83}$ two military case series, ${ }^{84,85}$ one military case study, ${ }^{86}$ and one military case report. ${ }^{87}$ The included studies are summarized in Table 1 . None of the studies reported on all of the criteria, with $36 \%-87 \%$ of the criteria being met. No published high-quality studies were found, all published studies had very low evidence according to GRADE, mostly due to their observational character and small sample size. ${ }^{10}$
A detailed quality appraisal is available as Appendix III (available online only).

Some of the studies included tourniquets applied in the emergency department alongside tourniquets applied in the prehospital setting. When the two groups were clearly differentiated, only the report on the prehospital tourniquet application group was reported.

\section{Mortality}

Fifty studies reported mortality in patients treated with tourniquet. Twenty-seven of these were either case reports or had less than 20 participants and were not included in assessing the primary outcome. ${ }^{11,13,37,44,46,50-63,65,71,77,78,84-87}$ Twenty-three studies were included to assess mortality. 12,36,38-43,45,47-49,64,66,67,69,73,74,79-83 Some of the studies reported data from the same population/database. Figure 2 shows data extracted from the latest published study to report mortality rate, consisting of ten civilian and seven military studies. ${ }^{12,36,38-42,45,47-49,69,73,74,79,81,83}$ The figure shows the reported survival, publication year, and sample size in each of these included studies. The studies reported a survival rate between $87 \%-100 \%$. None of the studies were randomized controlled studies, and studies with comparison groups were hampered by unclear indications for 


\begin{tabular}{|c|c|c|c|c|}
\hline \multicolumn{5}{|c|}{ Civilian Studies } \\
\hline Author Country Year Ref. No. & Study Type & Study Size Patients with TQ & TQ Time & Outcomes \\
\hline Kalish USA $2008^{37}$ & OR & 11 & 75 min (avg.) & $\begin{array}{l}\text { Survival rate: } 90.9 \% \\
\text { Fasciotomy: } 18.2 \%\end{array}$ \\
\hline Rtshiladze Australia $2011^{51}$ & CS & 2 & & Survival rate: $100 \%$ \\
\hline Passos Canada $2014^{50}$ & OR & 8 & & \begin{tabular}{|l|} 
Survival rate: $100 \%$ \\
Transfusions: 4 units (avg.) \\
Compartment syndrome: $0 \%$
\end{tabular} \\
\hline Callaway USA $2015^{52}$ & CS & 4 & 70.5 min (avg.) & $\begin{array}{l}\text { Survival rate: } 100 \% \\
\text { Transfusions: } 4.67 \text { units (avg.) } \\
\text { Amputation: } 0 \% \\
\text { Lasting nerve palsy: } 0 \% \\
\text { Fasciotomy: } 75 \%\end{array}$ \\
\hline King USA $2015^{49}$ & OR & 27 & & Survival rate: $100 \%$ \\
\hline Kue USA $2015^{36}$ & OR & 98 & $15 \min$ (avg.) & Survival rate: $89.8 \%$ \\
\hline Leonard USA $2015^{42}$ & OR & 61 & 21 min (median) & $\begin{array}{l}\text { Survival rate: } 90.2 \% \\
\text { Transfusions: } 7.4 \text { units (avg.) } \\
\text { Lasting nerve palsy: } 0 \% \\
\text { Compartment syndrome: } 0 \% \\
\text { Fasciotomy: } 6.6 \% \\
\text { Infection: } 6.6 \% \\
\end{array}$ \\
\hline Scerbo USA $2016^{43}$ & OR & 105 & & $\begin{array}{l}\text { Survival rate: } 93.3 \% \\
\text { Transfusions: } 2 \text { units (avg.) } \\
\text { Amputation: } 0 \% \\
\text { Lasting nerve palsy: } 0 \% \\
\text { Compartment syndrome: } 1.9 \% \\
\text { Fasciotomy: } 26.7 \%\end{array}$ \\
\hline Ballas France $2017^{44}$ & OR & 4 & & Survival rate: $100 \%$ \\
\hline Scerbo USA $2017^{45}$ & OR & 306 & & $\begin{array}{l}\text { Survival rate: } 93.1 \% \\
\text { Transfusions: } 3 \text { units (avg.) } \\
\text { Compartment syndrome: } 1.6 \%\end{array}$ \\
\hline Duignan USA $2018^{46}$ & OR & 5 & & Survival rate: $80 \%$ \\
\hline Teixeira USA $2018^{47}$ & OR & 181 & $77.3 \min$ (avg.) & $\begin{array}{l}\text { Survival rate: } 96.1 \% \\
\text { Transfusions: } 5 \text { units (avg.) } \\
\text { Infection: } 13.8 \%\end{array}$ \\
\hline
\end{tabular}

Table 1. An Overview and Summary of the Included Studies, Excluding Case Reports (continued) 


\begin{tabular}{|c|c|c|c|c|}
\hline \multicolumn{5}{|c|}{ Civilian Studies } \\
\hline Author Country Year Ref. No. & Study Type & Study Size Patients with TQ & TQ Time & Outcomes \\
\hline Smith USA $2019^{48}$ & OR & 238 & 34.9 min (avg.) & $\begin{array}{l}\text { Survival rate: } 91.2 \% \\
\text { Transfusions: } 2.2 \text { units (avg.) } \\
\text { Compartment syndrome: } 5.9 \% \\
\text { Fasciotomy: } 11.3 \% \\
\text { Infection: } 8 \%\end{array}$ \\
\hline Lakstein Israel $2003^{72}$ & OR & 91 & $83 \min$ (avg.) & \\
\hline Pilgram - Larsen Norway $2004^{11}$ & OR & 18 & & Survival rate: $83 \%$ \\
\hline Mucciarone USA $2006^{86}$ & CSt & 2 & & $\begin{array}{l}\text { Survival rate: } 100 \% \\
\text { Amputation: } 0 \%\end{array}$ \\
\hline Brodie UK $2007^{73}$ & OR & 70 & & $\begin{array}{l}\text { Survival rate: } 87 \% \\
\text { Compartment syndrome: } 2.9 \%\end{array}$ \\
\hline Dayan Israel $2008^{84}$ & CS & 5 & 795 min (avg.) & $\begin{array}{l}\text { Survival rate: } 100 \% \\
\text { Lasting nerve palsy: } 0 \% \\
\text { Amputation: } 20 \% \\
\text { Compartment syndrome: } 20 \% \\
\text { Fasciotomy: } 20 \%\end{array}$ \\
\hline Kragh USA $2008^{64}$ & OP & 232 & $\begin{array}{c}78 \text { min (avg.) } \\
60 \text { min (median) }\end{array}$ & $\begin{array}{l}\text { Survival rate: } 86.6 \% \\
\text { Lasting nerve palsy: } 0.4 \% \\
\text { Amputation: } 0.4 \% \\
\text { Compartment syndrome: } 0 \% \\
\text { Fasciotomy: } 41.4 \%\end{array}$ \\
\hline Clasper UK $2009^{75}$ & OR & - & 60 min (median) & Infection: 18 patients \\
\hline Kragh USA $2009^{66}$ & OP & 232 & & $\begin{array}{l}\text { Survival rate: } 86.6 \% \\
\text { Lasting nerve palsy: } 0.4 \% \\
\text { Amputation: } 0 \%\end{array}$ \\
\hline Brown UK $2010^{76}$ & OR & 23 & & Infection: $52.2 \%$ \\
\hline Gerhardt USA $2011^{77}$ & OR & 8 & & Survival rate: $75 \%$ \\
\hline Kotwal USA $2011^{12}$ & OR & 66 & & Survival rate: $94 \%$ \\
\hline Kragh USA $2011^{67}$ & OP & 499 & & Survival rate: $86.6 \%$ \\
\hline Kragh USA $2011^{68}$ & OP & 499 & & $\begin{array}{l}\text { Lasting nerve palsy: } 0.2 \% \\
\text { Fasciotomy: } 29.7 \%\end{array}$ \\
\hline Cheng China $2012^{78}$ & OR & 7 & & Survival rate: $29 \%$ \\
\hline Kragh USA $2013^{69}$ & OP & 727 & & Survival rate: $88 \%$ \\
\hline Kragh USA $2015^{79}$ & OR & 1272 & & Survival rate: $92 \%$ \\
\hline Kragh USA $2015^{80}$ & OR & 720 & & $\begin{array}{l}\text { Survival rate: } 88 \% \\
\text { Transfusions: } 12 \text { units (avg.) }\end{array}$ \\
\hline Dunn USA $2016^{81}$ & OR & 24 & & Survival rate: $96 \%$ \\
\hline Dunn USA $2016^{82}$ & OR & 6 & & Survival rate: $83 \%$ \\
\hline
\end{tabular}

Table 1. An Overview and Summary of the Included Studies, Excluding Case Reports (continued) 


\begin{tabular}{|l|c|c|c|l|}
\hline \multicolumn{5}{|c|}{ Civilian Studies } \\
\hline Author Country Year Ref. No. & Study Type & Study Size Patients with TQ & TQ Time & \multicolumn{1}{c|}{ Outcomes } \\
\hline Shlaifer Israe $2017^{83}$ & OR & 90 & $\begin{array}{l}\text { Survival rate: } 88 \% \\
\text { Lasting nerve palsy: } 3.3 \% \\
\text { Fasciotomy: } 8.9 \%\end{array}$ \\
\hline Staudt USA ${ }^{70}$ & & & & \\
\hline
\end{tabular}

Table 1. (continued). An Overview and Summary of the Included Studies, Excluding Case Reports

Abbreviations: CS, case series; CSt, case study; OP, observational prospective; OR, observational retrospective; TQ, tourniquet.

tourniquet placement and bias due to a risk of more severe injuries in the tourniquet group.

Overall, the military studies reported similar mortality rates in patients treated with tourniquets and patients who were not, despite the patients in the tourniquet group being more severely injured. Early application before the onset of shock was strongly associated with increased survival. One study ${ }^{67}$ found that $96 \%$ of patients survived when the tourniquet was placed before the onset of shock compared to four percent of patients who received a tourniquet later. Patients treated with prehospital tourniquet (89\%) also had higher survival rates than those who received a tourniquet upon arrival at the hospital (76\%-78\%). ${ }^{66,67}$

Overall, studies indicated a survival benefit for patients treated with tourniquets in a civilian setting. Patients treated with prehospital tourniquet had a lower incidence of shock when arriving at the hospital compared to those who were not treated with tourniquet. ${ }^{48}$ One study reported that death from hemorrhagic shock was more frequent in patients who received a tourniquet in-hospital (14\%) compared to those who received a prehospital tourniquet (three percent). ${ }^{45}$ Most studies reported an average tourniquet application time less than two hours.

\section{Blood Transfusions}

Seventeen studies reported on blood transfusions in patients treated with tourniquets: nine civilian observational studies, ${ }^{38,40,42,43,45,47,48,50,52}$ three military observational studies, ${ }^{74,80,85}$ and five civilian case reports. ${ }^{53,54,59,62,63}$ In the majority of the civilian studies with a control group, patients with a prehospital tourniquet received fewer blood products than patients not treated with tourniquets or if the tourniquets were placed in-hospital. In the military studies, the tourniquet patients received more blood products than their respective control groups. In one study, ${ }^{80}$ the difference between the study groups was significant, but most of the patients in the tourniquet group also had non-extremity injuries, which may have affected the data.

\section{Other Complications}

Thirty-five of the studies reported on complications associated with the use of tourniquets, 21 in the civilian setting and 14 in the military setting; 10 of these were case reports. Fifteen studies reported on nerve palsy associated with the use of tourniquet. $^{36,40,42,43,48,52,64,66-68,72-74,83,84}$ Six civilian studies reported on nerve palsies attributed to the use of tourniquet in 18 of 465 patients. One study found that tourniquets were not associated with nerve palsies when comparing two groups of patients (127 treated with tourniquet versus 77 patients not treated with tourniquet). ${ }^{48}$ Neurological complications seemed to be few and most were transient.
Nine studies reported on amputations as a complication of the use of a tourniquet, one of which was a case report. Four of the studies were civilian ${ }^{38,43,52,62}$ and five were military. ${ }^{64,66,74,84,86}$ To summarize, very few amputations were solely due to the use of tourniquets, but the few casuistic amputations related to tourniquet use per se were mainly related to improvised tourniquets and prolonged tourniquet application time.

A need for fasciotomy and/or compartment syndrome in patients treated with tourniquet was reported in 17 studies, three of which were case reports. ${ }^{37,38,40,42,43,45,48,50,52,55,58,64,68,73,83,84,87}$ Fasciotomy seemed to be a frequent treatment modality after the use of tourniquets, and compartment syndrome was not infrequent if fasciotomy was not performed. Tourniquet application time greater than two hours seemed to increase fasciotomy rates. ${ }^{68}$

Seven studies reported on infections associated with tourniquet use: five civilian ${ }^{38,40,42,47,48}$ and two military studies. ${ }^{75,76}$ The civilian studies had a total of 764 patients with tourniquets, 67 of which were reported to have a wound infection (nine percent). Tourniquets were not associated with a difference in secondary infection rates compared to the non-tourniquet groups.

\section{Discussion}

Currently available knowledge did not allow for a systematic review with meta-analyses. Most studies were cohorts and case reports, and no randomized controlled studies were found. Thus, a descriptive synthesis was performed. Most studies indicated that early application of a tourniquet before the onset of shock increased survival in patients bleeding from an extremity. The difference in survival between patients treated with tourniquets and those without was low, possibly because patients treated with tourniquets were more severely injured. This suggests that tourniquets may play a central role in saving the lives of patients with non-controllable extremity bleeding. The studies also showed that patients with isolated extremity bleeding required fewer blood transfusions when treated with tourniquets, and that the adverse effects of tourniquet use were few and predictable.

The studies were dominated by military studies before 2012 and civilian studies after 2015. This may be due to the civilian focus on implementing military guidelines in mass-casualty events. When comparing the military studies with the civilian studies, differences in the mechanism of injury were found. However, the indication for the use of tourniquets was similar: uncontrollable hemorrhage from the extremities. The tourniquet application time was considered to be an important factor. The application time was similar between the military and civilian studies, but considerably shorter in civilian urban areas.

Numerous complications from the use of tourniquets have been described. They seemed to be infrequent and many resolved. 


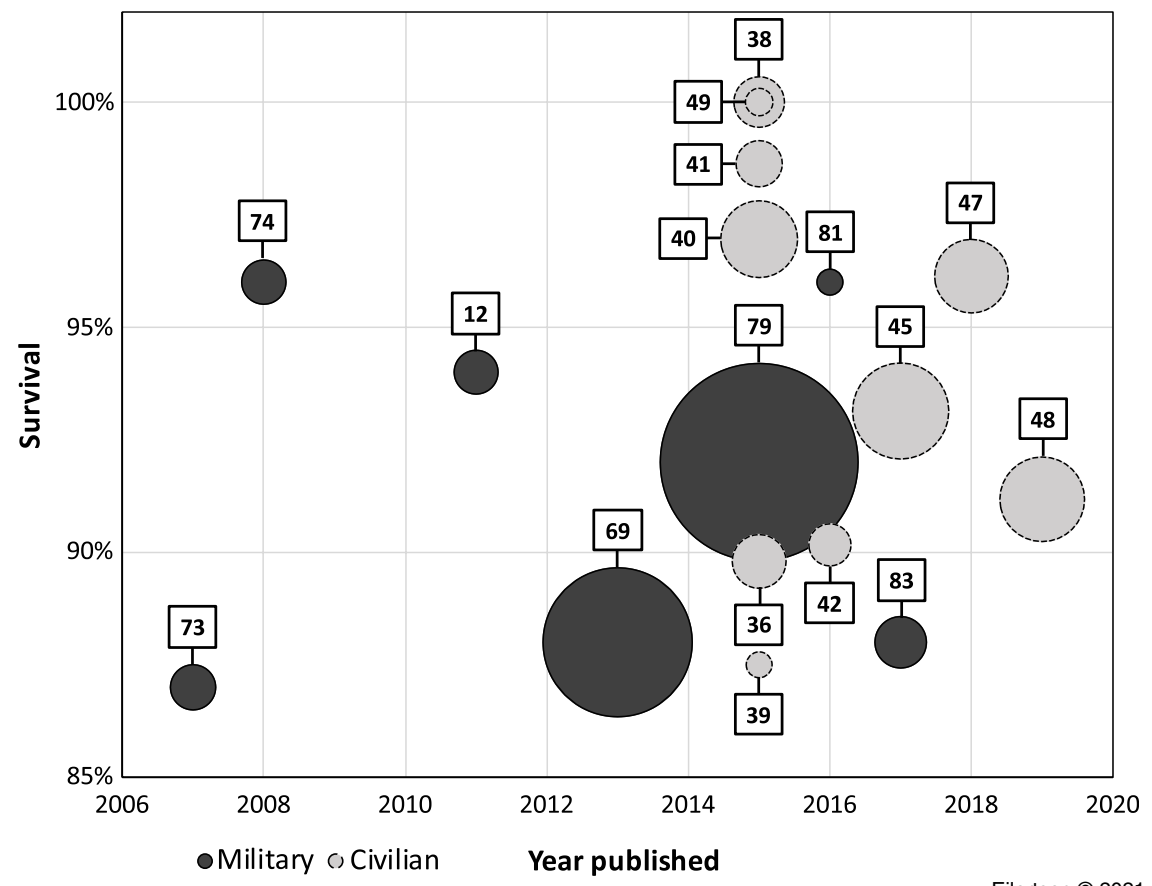

Figure 2. Studies Reporting on Mortality, Excluding Case Reports and Studies with Less Than 20 Participants.

Note: Circle size indicates the number of patients treated with tourniquet. The center of the circle indicates the survival rate. Each study is represented by its reference number.

However, in a life-over-limb situation, the risk seemed negligible. When the tourniquets were used correctly, the reports indicated hardly any risk of amputation due to the tourniquet. Improvised tourniquets seemed to be less effective than commercial tourniquets and may increase the risk of venous stasis and paradoxical bleeding.

The findings in this study correspond to those in the systematic reviews identified in the present search.

\section{Limitations}

All of the findings in this review have low to very low strength of evidence due to the observational character of the included studies. Most studies are biased, as patients who died before arriving at the hospital are not included in the analyzed databases. Despite the extensive search, there is a risk that relevant studies may have been missed. Three (Chinese and Cyrillic) studies were excluded due to language.

\section{Conclusion}

Despite low level of evidence in the studies identified, the studies consistently indicated that the use of a tourniquet was associated with increased survival in uncontrollable extremity bleeding in a civilian setting. The civilian and military studies reported similar findings and treatment efficiency, though military studies tended to have longer application times. Complications to tourniquet use seemed to be tightly related to application time, and application times less than two hours seemed to be reasonably safe in previously healthy patients. Application times in urban civilian settings were short.

\section{Author Contributions}

TW conceived the study. MW, KAE, and TW drafted the protocol. EJ and $\mathrm{GH}$ designed the literature search and $\mathrm{GH}$ performed the search. KAE and MW screened the papers, and all authors took part in manuscript drafting and critical discussion of study results and conclusions. All authors have read and approved the final version of the manuscript. TW takes responsibility for the integrity of the work as a whole.

\section{Supplementary Material}

To view supplementary material for this article, please visit https:// doi.org/10.1017/S1049023X20001284

\section{References}

1. Jacobs LM, Jr. The Hartford Consensus III: implementation of bleeding control. J Spec Oper Med. 2015;15(4):136-141.

2. Jacobs LM. The Hartford Consensus IV: a call for increased national resilience. Bull Am Coll Surg. 2016;101(3):17-24.

3. Jacobs LM, McSwain NE, Jr., Rotondo MF, et al. Improving survival from active shooter events: the Hartford Consensus. J Trauma Acute Care Surg. 2013;74(6):1399-1400.

4. Jacobs LM, Sinclair J, Rotondo M, et al. Active shooter and international mass-casualty events: The Hartford Consensus II. Bull Am Coll Surg. 2015;100(1 Suppl):35-39.

5. Gaarder C, Jorgensen J, Kolstadbraaten KM, et al. The twin terrorist attacks in Norway on July 22, 2011: the trauma center response. J Trauma Acute Care Surg. 2012;73(1): 269-275.

6. Moher D, Liberati A, TetzlaffJ, et al. Preferred Reporting Items for Systematic Reviews and Meta-Analyses: the PRISMA statement. PLOS Medicine. 2009;6(7):e1000097.
7. Rayyan - a web and mobile app for systematic reviews. Systematic Reviews. 2016;5:210.

8. Thomson Reuters PP. EndNote X9; 2019.

9. Flin R, Maran N. Identifying and training non-technical skills for teams in acute medicine. Qual Saf Health Care. 2004;13(Suppl 1):i80-84.

10. Guyatt $\mathrm{GH}$, Oxman AD, Vist GE, et al. GRADE: an emerging consensus on rating quality of evidence and strength of recommendations. BMJ. 2008;336(7650):924-926.

11. Pillgram-Larsen J. Compression bandage, not tourniquet. Experience in 68 patients with traumatic amputation after mine injuries. ResearchGate. https://www.researchgate. net/publication/235023783_Compression_Bandage_Not_Tourniquet_Experience_in_ 68_Patients_With_Traumatic_Amputation_after_Mine_Injuries. Accessed June 2020.

12. Kotwal RS, Montgomery HR, Kotwal BM, et al. Eliminating preventable death on the battlefield. Arch Surg. 2011;146(12):1350-1358. 
13. Hauschild SW, Noldge-Schomburg G, Hoitz J. Hemostasis with a tourniquet in preclinical emergency medicine. German Interdisciplinary Journal of Emergency Medicine. 2013;16(4):291-304.

14. Fox CJ, Patel B, Clouse WD. Update on wartime vascular injury. Perspect Vasc Surg Endovasc Ther. 2011;23(1):13-25.

15. Hodgetts TJ, Mahoney PF. The military tourniquet: a response. J R Army Med Corps 2007;153(1):12-15.

16. Lee C, Porter KM, Hodgetts TJ. Tourniquet use in the civilian prehospital setting Emerg Med J. 2007;24(8):584-587.

17. Parker PJ, Clasper J. The military tourniquet. J R Army Med Corps. 2007; 153(1):10-12.

18. Bridges E, Biever K. Advancing critical care: joint combat casualty research team and joint theater trauma system. AACN Adv Crit Care. 2010;21(3):260-276.

19. Kragh JF, Jr. Use of tourniquets and their effects on limb function in the modern combat environment. Foot Ankle Clin. 2010;15(1):23-40.

20. Ozturk G, Yildiran N, Kara K. When should a tourniquet be released? TAF Preventive Medicine Bulletin. 2012;11(5):1-6.

21. Lang CL, Lauridsen T, Boel T. The use of prehospital tourniquets in life-threatening in extremity traumas [Danish]. Ugeskr Laeger. 2014;176(36).

22. Drew B, Bennett BL, Littlejohn L. Application of current hemorrhage control techniques for backcountry care: part one, tourniquets and hemorrhage control adjuncts. Wilderness Environ Med. 2015;26(2):236-245.

23. Danguy des Deserts M, Commandeur D, Thill C, et al. Hemostatic tourniquet. Praticien en Anesthesie Reanimation. 2016;20(4):160-166.

24. Kragh JF, Jr., Dubick MA. Bleeding control with limb tourniquet use in the wilderness setting: review of science. Wilderness Environ Med. 2017;28(2):S25-S32.

25. Fox N, Rajani RR, Bokhari F, et al. Evaluation and management of penetrating lower extremity arterial trauma: an eastern association for the surgery of trauma practice management guideline. J Trauma Acute Care Surg. 2012;73(5): S315-S320.

26. Stewart SK, Duchesne JC, Khan MA. Improvised tourniquets: obsolete or obligatory? J Trauma Acute Care Surg. 2015;78(1):178-183.

27. Butler FK. Military history of increasing survival: the US military experience with tourniquets and hemostatic dressings in the Afghanistan and Iraq conflicts. J Spec Oper Med. 2015;15(4):149-152.

28. Paul S, Debien B. Tourniquet use in civil and military medicines [French]. Ann Fr Anesth Reanim. 2014;33(4):248-255.

29. Niven M, Castle N. Use of tourniquets in combat and civilian trauma situations. Emerg Nurse. 2010;18(3):32-36.

30. Mawhinney AC, Kirk SJ. A systematic review of the use of tourniquets and topical hemostatic agents in conflicts in Afghanistan and Iraq. J $R$ Nav Med Serv. 2015; 101(2):147-154.

31. Wright G, McDonald S, Smith G. Should civilian prehospital emergency care provision include tourniquets for the management of uncontrolled traumatic hemorrhage? Australasian Journal of Paramedicine. 2015;12(4).

32. Hossfeld B, Lechner R, Josse F, et al. Prehospital application of tourniquets for lifethreatening extremity hemorrhage: systematic review of literature. Unfallchirurg. 2018;121(7):516-529.

33. Kauvar DS, Dubick MA, Walters TJ, et al. Systematic review of prehospital tourniquet use in civilian limb trauma. I Trauma Acute Care Surg. 2018;84(5):819-825.

34. Beaucreux C, Vivien B, Miles E, et al. Application of tourniquet in civilian trauma: systematic review of the literature. Anaesth Crit Care Pain Med. 2018; 37(6):597-606

35. Bulger EM, Snyder D, Schoelles K, et al. An evidence-based prehospital guideline for external hemorrhage control: American College of Surgeons Committee on Trauma. Prehosp Emerg Care. 2014;18(2):163-173.

36. Kue RC, Temin ES, Weiner SG, et al. Tourniquet use in a civilian Emergency Medical Services setting: a descriptive analysis of the Boston EMS experience. Prehosp Emerg Care. 2015;19(3):399-404

37. Kalish J, Burke P, Feldman J, et al. The return of tourniquets. Original research evaluates the effectiveness of prehospital tourniquets for civilian penetrating extremity injuries. JEMS. 2008;33(8):44-46

38. Inaba K, Siboni S, Resnick S, et al. Tourniquet use for civilian extremity trauma J Trauma Acute Care Surg. 2015;79(2):232-237.

39. Ode G, Studnek J, Seymour R, et al. Emergency tourniquets for civilians: can military lessons in extremity hemorrhage be translated? J Trauma Acute Care Surg. 2015; 79(4):586-591.

40. Schroll R, Smith A, McSwain NE, Jr., et al. A multi-institutional analysis of prehospital tourniquet use. J Trauma Acute Care Surg. 2015;79(1):10-14.

41. Zietlow JM, Zietlow SP, Morris DS, et al. Prehospital use of hemostatic bandages and tourniquets: translation from military experience to implementation in civilian trauma care. J Spec Oper Med. 2015;15(2):48-53.

42. Leonard J, Zietlow J, Morris D, et al. A multi-institutional study of hemostatic gauze and tourniquets in rural civilian trauma. J Trauma Acute Care Surg. 2016;81(3):441-444.
43. Scerbo MH, Mumm JP, Gates K, et al. Safety and appropriateness of tourniquets in 105 civilians. Prehosp Emerg Care. 2016;20(6):712-722

44. Ballas R, Saetta G, Peuchot C, et al. Clinical features of 27 shark attack cases on La Reunion Island. J Trauma Acute Care Surg. 2017;82(5):952-955.

45. Scerbo MH, Holcomb JB, Taub E, et al. The trauma center is too late: major limb trauma without a prehospital tourniquet has increased death from hemorrhagic shock. J Trauma Acute Care Surg. 2017;83(6):1165-1172.

46. Duignan KM, Lamb LC, DiFiori MM, et al. Tourniquet use in the prehospital setting: are they being used appropriately? Am J Disaster Med. 2018;13(1):37-43.

47. Teixeira PGR, Brown CVR, Emigh B, et al. Civilian prehospital tourniquet use is associated with improved survival in patients with peripheral vascular injury. $J \mathrm{Am}$ Coll Surg. 2018;226(5):769-776.

48. Smith AA, Ochoa JE, Wong $\mathrm{S}$, et al. Prehospital tourniquet use in penetrating extremity trauma: decreased blood transfusions and limb complications. J Trauma Acute Care Surg. 2019;86(1):43-51

49. King DR, Larentzakis A, Ramly EP, et al. Tourniquet use at the Boston Marathon bombing: lost in translation. J Trauma Acute Care Surg. 2015;78(3):594-599.

50. Passos E, Dingley B, Smith A, et al. Tourniquet use for peripheral vascular injuries in the civilian setting. Injury. 2014;45(3):573-577.

51. Rtshiladze MA, Andersen SP, Nguyen DQA, et al. The 2009 Sydney shark attacks: case series and literature review. J Surg. 2011;81(5):345-351.

52. Callaway DW, Robertson J, Sztajnkrycer MD. Law enforcement-applied tourniquets: a case series of life-saving interventions. Prehosp Emerg Care. 2015;19(2):320-327.

53. Gouk C, Pasricha D, Lingathas S. Shark attack: the emergency presentation and management. BMJ Case Rep. 2015

54. Fludger S, Bell A. Tourniquet application in a rural Queensland HEMS environment Air Med J. 2009;28(6):291-293.

55. Mullins J, Harrahill M. Use of a tourniquet after a gunshot wound to the thigh. JEmerg Nurs. 2009;35(3):265-267.

56. Polk T, Sims C. Life and limb: tourniquet saves man severely injured in vehicle crash JEMS. 2012;37(9):30-31.

57. Risk GC, Augustine J. Extreme bleeds: recommendations for tourniquets in civilian EMS. JEMS. 2012;37(3):76-81

58. Eikermann M, Velmahos G, Abbara S, et al. Case records of the Massachusetts General Hospital. Case 11-2014. A man with traumatic injuries after a bomb explosion at the Boston Marathon. N Engl J Med. 2014;370(15):1441-1451.

59. Robertson J, McCahill P, Riddle A, et al. Another civilian life saved by law enforcement-applied tourniquets. J Spec Oper Med. 2014;14(3):7-11.

60. Zhang X, Bai X, Zhou Q. First-aid treatments of crush injuries after earthquake: 2 special cases. Am J Emerg Med. 2014;32(7):817.

61. Jacobs LM, Burns KJ, Priest HS, et al. Use of a tourniquet by LIFE STAR air medical crew: a case report. Conn Med. 2015;79(9):537-541.

62. Malo C, Bernardin B, Nemeth J, et al. Prolonged prehospital tourniquet placement associated with severe complications: a case report. CJEM. 2015;17(4):443-446

63. Kippnich M, Jelting Y, Kraus M, et al. Emergency care of trauma patients with the Bavarian "Rebel" Kit. Anasthesiol Intensivmed Notfallmed Schmerzther. 2018;53(7): 551-558.

64. Kragh JF, Jr., Walters TJ, Baer DG, et al. Practical use of emergency tourniquets to stop bleeding in major limb trauma. J Trauma-Injury Infect Crit Care. 2008, 64(2):S38-50.

65. Tien HC, Jung V, Rizoli SB, et al. An evaluation of tactical combat casualty care interventions in a combat environment. J Am Coll Surg. 2008;207(2):174-178.

66. Kragh Jr JF, Walters TJ, Baer DG, et al. Survival with emergency tourniquet use to stop bleeding in major limb trauma. Ann Surg. 2009;249(1):1-7.

67. Kragh Jr JF, Littrel ML, Jones JA, et al. Battle casualty survival with emergency tour niquet use to stop limb bleeding. J Emerg Med. 2011;41(6):590-597.

68. Kragh Jr JF, O’Neill ML, Walters TJ, et al. Minor morbidity with emergency tourniquet use to stop bleeding in severe limb trauma: research, history, and reconciling advocates and abolitionists. Mil Med. 2011;176(7):817-823.

69. Kragh Jr JF, Beebe DF, O’Neill ML, et al. Performance improvement in emergency tourniquet use during the Baghdad surge. Am J Emerg Med. 2013;31(5):873-875.

70. Staudt A, Gurney J, Valdez-Delgado K, et al. Factors associated with trauma patients' length of stay at Role 2 facilities in Afghanistan, October 2009 to September 2014. J Trauma Acute Care Surg. 2018;85(1):S140-S144.

71. Holcomb JB, McMullin NR, Pearse L, et al. Causes of death in US Special Operation Forces in the global war on terrorism: 2001-2004. Ann Surg. 2007;245(6):986-991.

72. Lakstein D, Blumenfeld A, Sokolov T, et al. Tourniquets for hemorrhage control on the battlefield: a 4-year accumulated experience. J Trauma-Injury Infect Crit Care. 2003;54(5):S221-S225

73. Brodie S, Hodgetts TJ, Ollerton J, et al. Tourniquet use in combat trauma: UK military experience. J R Army Med Corps. 2007;153(4):310-313.

74. Beekley AC, Sebesta JA, Blackbourne LH, et al. Prehospital tourniquet use in Operation Iraqi Freedom: effect on hemorrhage control and outcomes. J TraumaInjury Infect Crit Care. 2008;64(2):S28-37. 
75. Clasper JC, Brown KV, Hill P. Limb complications following pre-hospital tourniquet use. J R Army Med Corps. 2009;155(3):200-202.

76. Brown KV, Murray CK, Clasper JC. Infectious complications of combat-related mangled extremity injuries in the British military. J Trauma-Injury Infect Crit Care. 2010;69:S109-115.

77. Gerhardt R, Berry J, Mabry R, et al. Analysis of life-saving interventions performed by out-of-hospital combat medical personnel. Acad Emerg Med. 2011;1(Suppl):S83.

78. Cheng CZ, Zhao DH, Li QY, et al. Causes of inpatient death for patients with warfare-related limb trauma and logistic regression analysis of the risk factors. Eur J Trauma Emerg Surg. 2012;38(2):107-112.

79. Kragh JF, Dubick MA, Aden JK, et al. US Military use of tourniquets from 2001 to 2010. Prehosp Emerg Care. 2015;19(2):184-190.

80. Kragh JF, Jr., Nam JJ, Berry KA, et al. Transfusion for shock in US military war casualties with and without tourniquet use. Ann Emerg Med. 2015;65(3):290-296.

81. Dunn JC, Fares A, Kusnezov N, et al. US service member tourniquet use on the battlefield: Iraq and Afghanistan 2003-2011. Trauma (UK). 2016;18(3):216-220.
82. Dunn JC, Kusnezov N, Schoenfeld AJ, et al. Vascular injuries in combat-specific soldiers during Operation Iraqi Freedom and Operation Enduring Freedom. Ann Vasc Surg. 2016;35:30-37.

83. Shlaifer A, Yitzhak A, Baruch EN, et al. Point of injury tourniquet application during Operation Protective Edge-what do we learn? J Trauma Acute Care Surg. 2017; 83(2):278-283.

84. Dayan L, Zinmann C, Stahl S, et al. Complications associated with prolonged tourniquet application on the battlefield. Mil Med. 2008;173(1):63-66.

85. Nelson TJ, Clark T, Stedje-Larsen ET, et al. Close proximity blast injury patterns from improvised explosive devices in Iraq: a report of 18 cases. J Trauma-Injury Infect Crit Care. 2008;65(1):212-217.

86. Mucciarone JJ, Llewellyn CH, Wightman JM. Tactical combat casualty care in the assault on Punta Paitilla Airfield. Mil Med. 2006;171(8):687-690.

87. Kragh JF, Jr., Baer DG, Walters TJ. Extended (16-hour) tourniquet application after combat wounds: a case report and review of the current literature. J Orthop Trauma. 2007;21(4):274-278. 